Graphical Abstract:

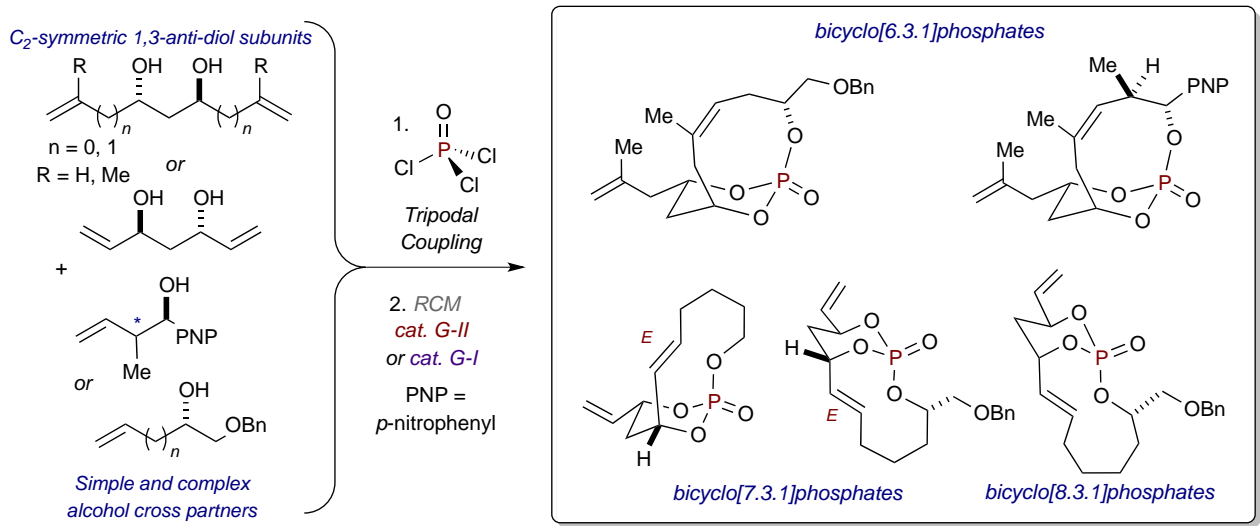

\title{
Phosphate Tether-Mediated Ring-Closing Metathesis for the Generation of Medium to Large, P-Stereogenic Bicyclo[n.3.1]phosphates
}

Soma Maitra, Jana L Markley, Rambabu Chegondi and Paul R. Hanson*

Department of Chemistry, University of Kansas, 1251 Wescoe Hall Drive, Lawrence, KS 66045-7582, phanson@ku.edu

Abstract: A phosphate tether-mediated ring-closing metathesis study towards the synthesis of $P$-stereogenic bicyclo[6.3.1]-, bicyclo[7.3.1]-, and bicyclo[8.3.1]phosphates is reported. This study demonstrates expanded utility of phosphate tether-mediated desymmetrization of $C_{2}$-symmetric, 1,3-anti-diol dienes in generating complex medium to large, $P$-stereogenic bicyclo[n.3.1]phosphates..

Keywords: phosphate tether, tripodal coupling, $P$-stereogenic phosphate, ring-closing metathesis, bicyclic phosphate triester, desymmetrization

\section{Introduction}

The development of new methods that allow for the construction of medium and large ring systems is a major challenge in modern organic synthesis. In particular, transformations that generate these rings via the stereoselective formation of new $\mathrm{C}-\mathrm{C}$ double bonds are fundamentally important in the synthesis of materials, natural products, and biologically active small molecules. ${ }^{1,2}$ In this regard, olefin metathesis, ${ }^{3}$ in combination with temporary tether strategies (i.e. silicon, ${ }^{4,5,6}$ ketal, ${ }^{7}$ carboxylate, ${ }^{8}$ etc.), has provided an elegant solution to the coupling of complex tether-partners, under mild reaction conditions, to provide small, medium, and large rings. Over the past decade, our group has utilized phosphate triesters as temporary tethers to desymmetrize a number of 1,3-anti-diol-containing dienes via ring-closing metathesis (RCM). ${ }^{9}$ Focused on the chemistry of the bicyclo[4.3.1]phosphate, ${ }^{10}$ this method served as the cornerstone in the synthesis en route to several natural products, including dolabelide $\mathrm{C},{ }^{11}$ salicylihalimide A (formal synthesis), ${ }^{12}$ (-)-tetrahydrolipstatin, ${ }^{13}$ (+)-strictifolione,${ }^{14}$ and lyngbouilloside. ${ }^{15}$ In 2013, we reported ${ }^{16}$ a detailed study of the effects of ring size and stereochemical complexity in the phosphate tether-mediated desymmetrization of $C_{2}$-symmetric 1,3 -anti diol dienes ${ }^{17}$ via RCM reaction to form $P$-stereogenic ${ }^{18,19}$ bicyclo[4.3.1]-, bicyclo[5.3.1]-, ${ }^{20}$ and bicyclo[7.3.1]phosphates ${ }^{21}$ (Figure 1). Herein, we wish to report the continuation of our investigation of phosphate tether-mediated RCM 
studies leading to medium (9-membered) and large (10- and 11-membered) ring systems-specifically bicyclo[6.3.1]- ${ }^{22}$ bicyclo[7.3.1]-, and bicyclo[8.3.1]phosphates. ${ }^{23}$ In combination with the previous work, this report highlights the potential of phosphate triesters to couple both simple and complex olefin-containing alcohols to provide structurally interesting bicyclic phosphate intermediates with potential synthetic and biological utility (Figure 1).
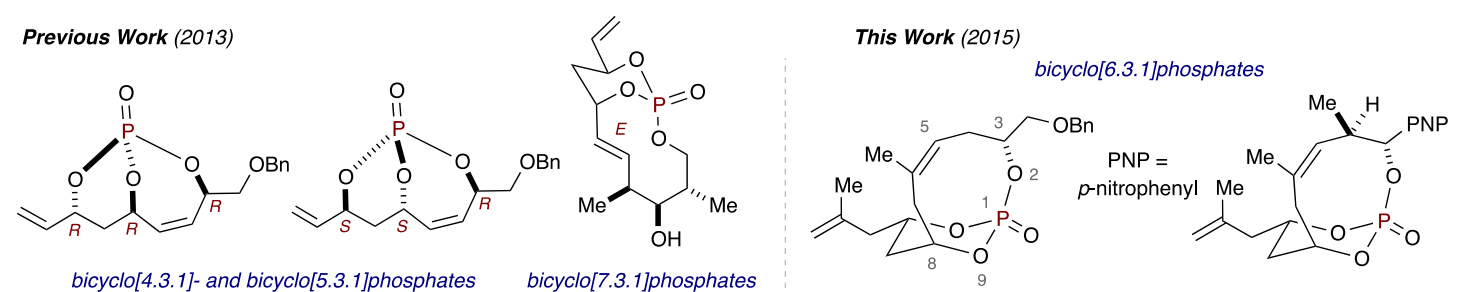

bicyclo[4.3.1]- and bicyclo[5.3.1]phosphates

bicyclo[7.3.1]phosphates

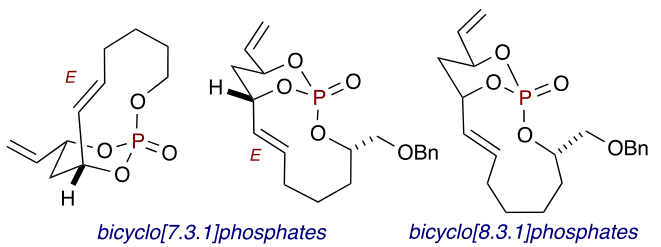

Figure 1 Summary of previous work and current work.

\section{Results and Discussion}

In 2013, we investigated the effect of ring-size, olefin substitution and the stereochemistry of coupling partners (tether-partners) upon the outcome of the

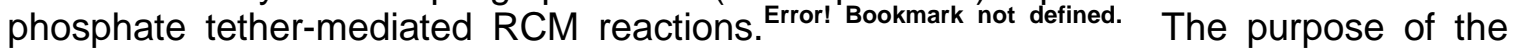
current study described herein is to further expand the scope of the substrates and to demonstrate the utility of phosphate tethers in the generation of complex medium to large ring systems. While the formation of small rings via $\mathrm{RCM}$ is usually facile, the synthesis of larger ring systems is significantly more challenging due to competitive oligomerization reactions, as well as the lack of stereoselectivity for the newly formed C$\mathrm{C}$ double bond. In this regard, temporary tether strategies, coupled with high dilution to prevent undesired intermolecular reactions, can be efficiently utilized to address these issues in the synthesis of larger ring systems-provided the behavior of the tether is fully understood within the context of each ring system.

\subsection{Synthesis of P-stereogenic bicyclo[6.3.1]phosphates}

Investigations commenced with the study of RCM reactions to form bicyclo[6.3.1]phosphates, which requires the generation of a 9-membered ring. Trienes 1.1 and 1.2 were derived from the coupling of alcohol (S)-1.3 with monochlorophosphates $(S, S)-1.4$ and $(R, R)-1.5$, respectively. Upon treatment with Grubbs second generation catalyst [G-II, $\left(\mathrm{ImesH}_{2}\right)\left(\mathrm{PCy}_{3}\right)(\mathrm{Cl})_{2} \mathrm{Ru}=\mathrm{CHPh}{ }^{24}$ in refluxing dichloromethane $\left(\mathrm{CH}_{2} \mathrm{Cl}_{2}\right)$, both bicyclo[6.3.1]phosphates cis-1.6 and trans-1.7 ${ }^{25}$ were formed in good yields (Scheme 1). These examples suggest that-like in the formation of bicyclo[5.3.1]phosphates (8-membered ring formation)-stereochemistry at the C3position of the tether-partner (ring numbering, Figure 1) does not affect the efficiency of the phosphate tether-mediated RCM reaction to bicyclo[6.3.1]phosphates. ${ }^{26}$ 


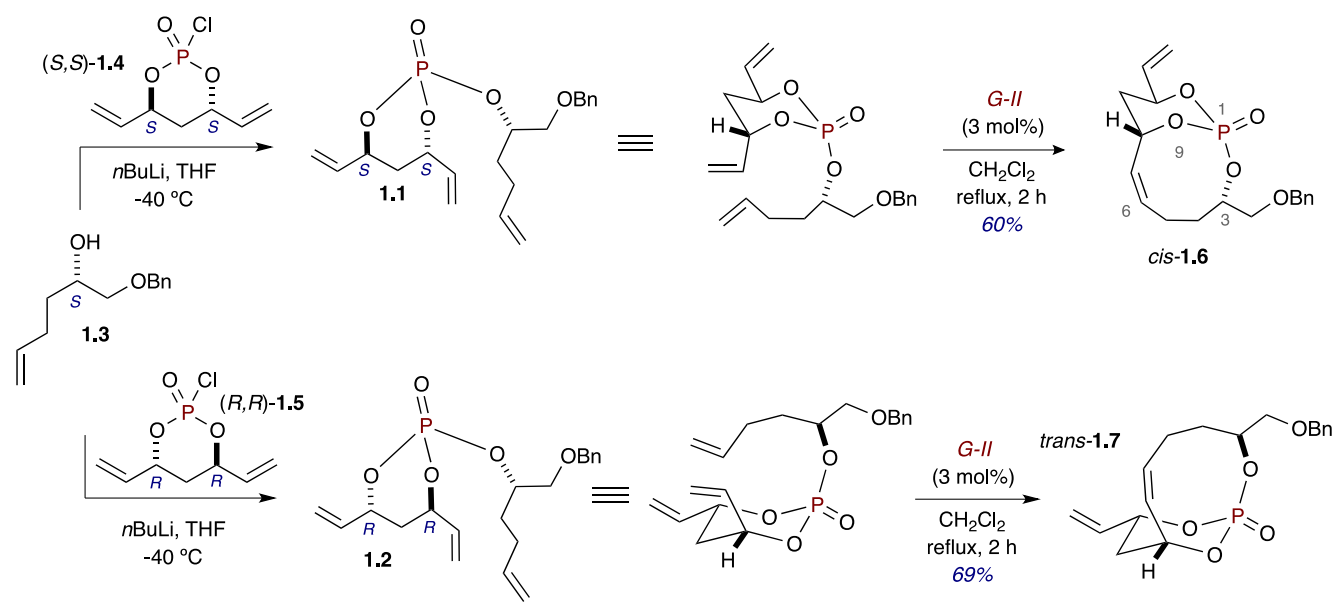

Scheme 1 Effect of C3-stereochemistry of alcohol tether-partner in the formation of bicyclo[6.3.1]phosphates.

To further probe substrate scope of the 9-membered ring formation, we extended the method to include tether-partners with greater stereochemical complexity. Thus, methyl-substituted homologated monochlorophosphate $(S, S)-2.1$ was coupled with homoallyl alcohol $(R)$-2.2 to generate triene $\mathbf{2 . 3}$ (Scheme 2). Upon treatment with G-II (3 mol \%, single addition), RCM successfully provided bicyclo[6.3.1]phosphate cis-2.4 in modest yield with exclusive Z-selectivity. In addition, the effect of the allylic methyl substituent in the corresponding alcohol tether-partner on the success of RCM was studied. For this purpose, methyl-substituted homologated monochlorophosphate $(S, S)$-2.1 was coupled with anti- and syn-crotylated alcohols 2.5 and 2.6 to generate trienes 2.7 and 2.8, respectively.
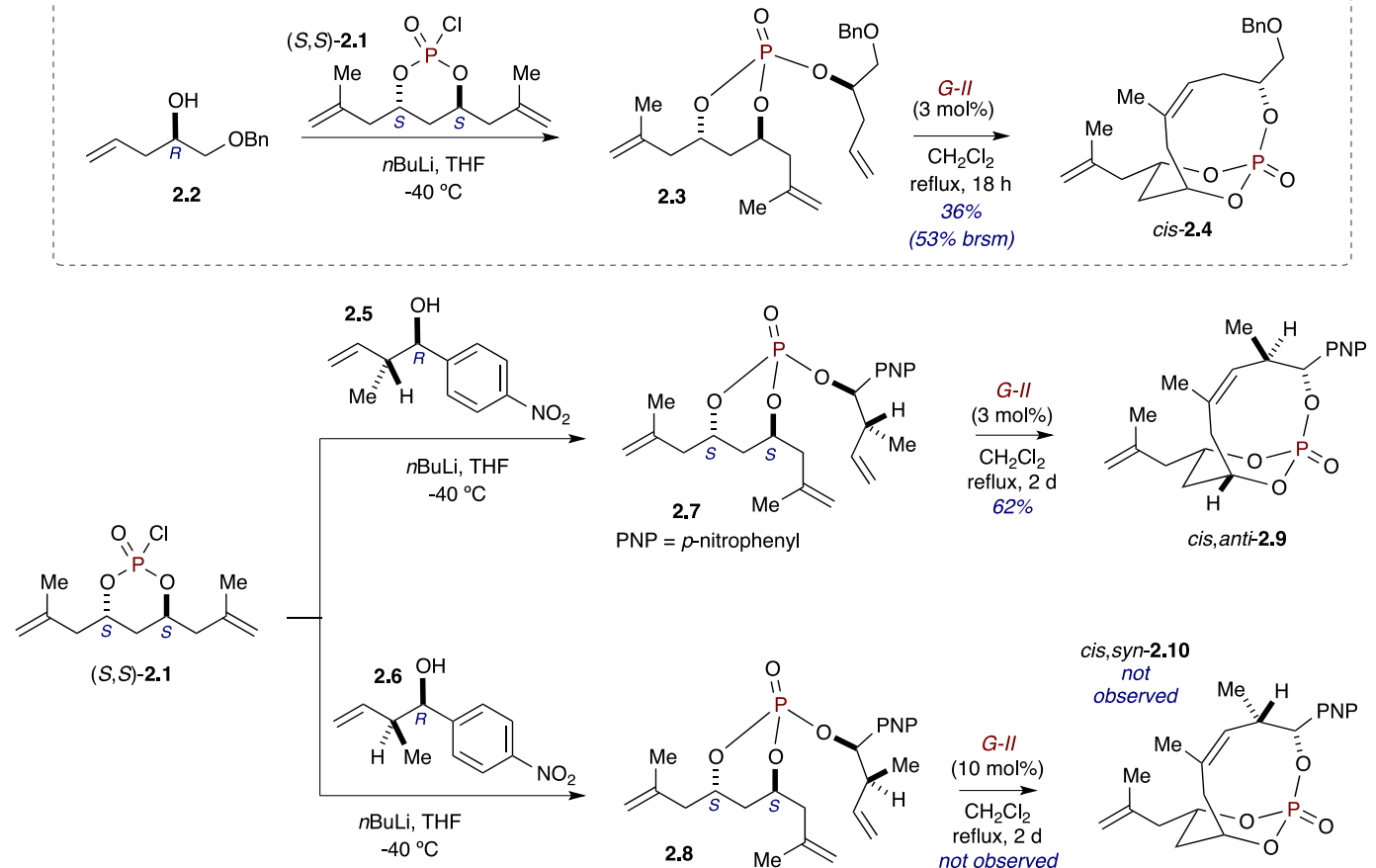

Scheme 2 Synthesis of stereochemically complex bicyclo[6.3.1]phosphates.

When subjected to the G-II catalyst ( $3 \mathrm{~mol} \%$ in one portion), triene $\mathbf{2 . 7}$ 
underwent RCM to provide the corresponding product cis, anti-2.9 ${ }^{27}$ (62\% yield); however, the bicyclo[6.3.1]phosphate (cis,syn-2.10) resulting from the RCM of triene 2.8 was not observed. It should be noted that this reactivity was unexpected, as the RCM reactions of homologous systems (with identical crotylated alcohol tether partners) to form bicyclo[5.3.1]phosphates provided selective cis,syn-product formation (2.11 in Figure 3); the corresponding cis, anti-product (2.12) was not observed.

To rationalize this seeming "flip" in reactivity, we developed plausible structures for high-energy Ru-metallocyclobutane intermediates based upon X-ray crystallographic analysis of the observed products cis-2.4 and cis,anti-2.9 (Figures 2 and 3). ${ }^{2829}$ As shown in the second depiction of the X-ray structures in Figure 2, the conformation of bicyclo[6.3.1]phosphates cis-2.4 and cis, anti-2.9 is such that the Ru-metallocyclobutane would presumably form on the more sterically accessible endo-face of the forming olefin. While unfavorable 1,3-steric interactions are present in both proposed intermediates (cis-2.4 and cis,anti-2.9), the successful formation of products implies that this interaction is not insurmountable, though longer reaction times were required to generate product.

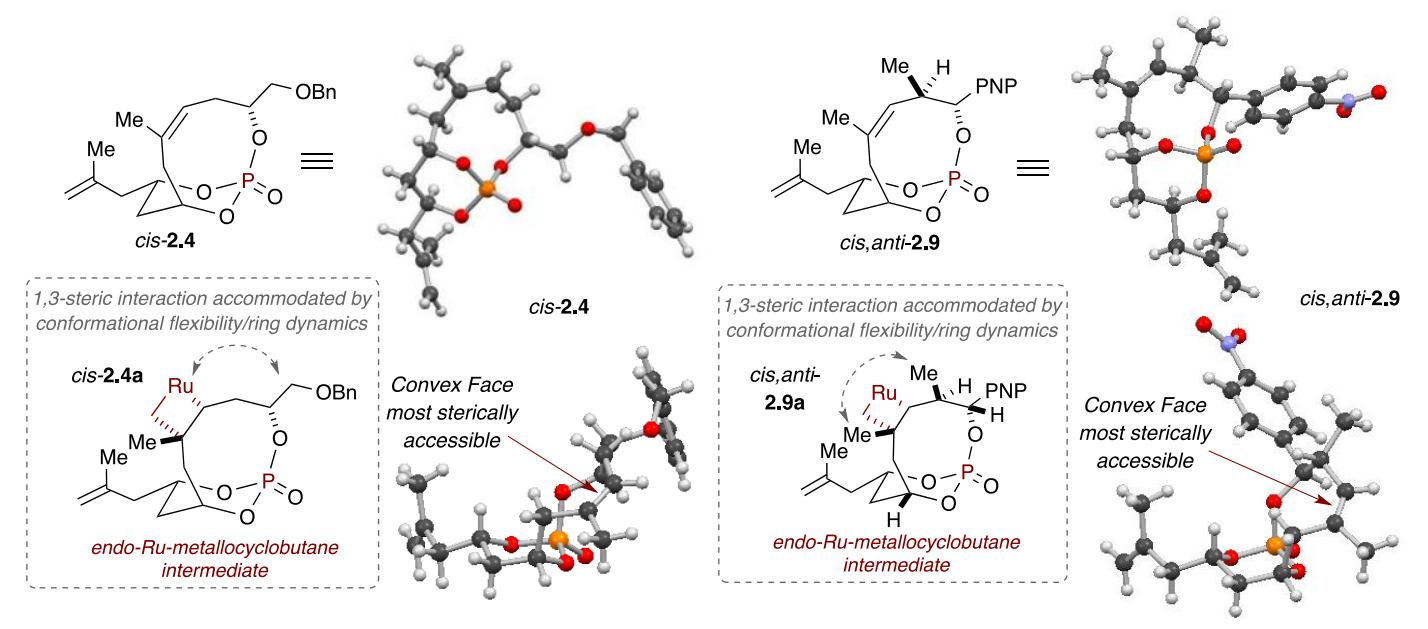

Figure 2 X-ray crystal structures of bicyclo[6.3.1]phosphates and plausible Ru-metallocyclobutane intermediates in the formation of cis-2.4 and cis, anti-2.9.

Taken collectively, these results-in combination with observations gathered from the studies involving the formation of bicyclo[5.3.1]phosphates ${ }^{\text {Error! Bookmark not }}$ defined. - have led to the proposed mechanistic rationale shown in Figure 3. In the case of bicyclo[5.3.1]phosphate formation, the concave nature of the bicyclic phosphate would suggest that Ru-metallocyclobutane formation is only energetically feasible when the Ru-metallocycle forms on the exo-face of the bicyclic phosphate (e.g. successful formation of cis, anti-2.11 via high energy intermediate cis,anti-2.11a, Figure 3) Based upon this assumption, bicyclic phosphate formation is impeded in cis, anti-2.12 where an unfavorable 1,2-steric interaction is present (e.g. cis,anti-2.12a), as well as in cis-2.13 where an unfavorable 1,3-steric interaction is present (e.g. cis-2.13a) between the exointermediate Ru-metallocyclobutane and substituents on the olefinic tether-partner. Likewise, in the case of cis,syn-2.10, an unfavorable 1,2-steric interaction is present (e.g. cis,syn-2.10a) between the endo-Ru-metallocyclobutane and the C4-methyl substituent of the olefinic tether-partner, preventing the formation of product. However, subtle differences in the ring dynamics of the 9 -membered ring (i.e. bicyclo[6.3.1]phosphate) 
versus the 8-membered ring (i.e. bicyclo[5.3.1]phosphate) may be responsible for the successful formation of cis,anti-2.9 (via cis,anti-2.9a), even in the presence of an unfavorable 1,3-steric interaction between the exo-methyl substituent on the $\mathrm{Ru}$ metallocyclobutane and the C4-methyl substituent of the alcohol tether-partner.

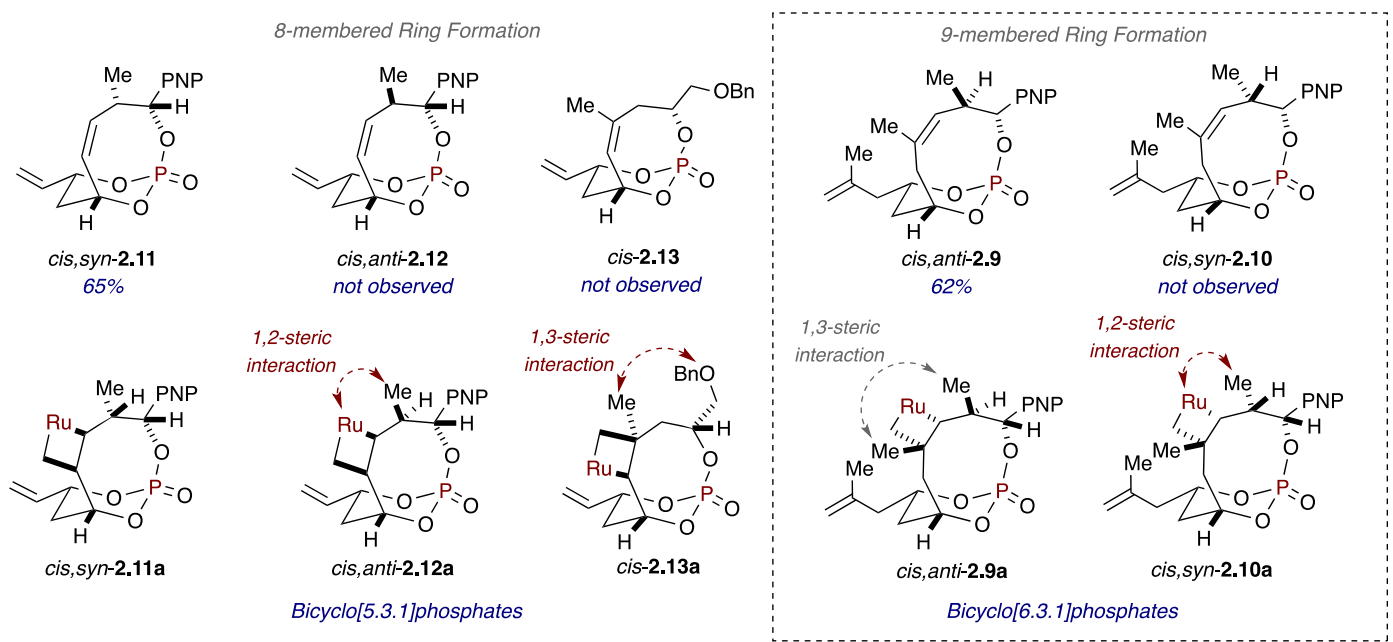

Figure 3 Plausible mechanistic rationale for the formation of bicyclo[5.3.1]- and bicyclo[6.3.1]phosphates.

\subsection{Synthesis of P-stereogenic bicyclo[7.3.1]phosphates}

Studies next focused on the formation of bicyclo[7.3.1]phosphates via an RCM reaction to provide a 10 -membered ring. While $Z$-selectivity for resultant olefin formation in $\mathrm{RCM}$ reactions to provide 9-membered rings is high, extension to 10-membered ring formation often leads to the opposite selectivity (E-olefin formation). ${ }^{30}$ However, in monocyclic silicon tether systems, reported Z-selectivity was high, even in 10- and 11membered ring formation., As such, it was unclear what selectivity would be observed in the context of bicyclo[7.3.1]phosphate generation prior to experimental confirmation. In 2013, we reported the synthesis of two, diastereomeric bicyclo[7.3.1]phosphate intermediates en route to a proposed synthesis of dictyostatin, which provided the E-configured products in good yield and high selectivity ( $d r>20: 1)$ [see Figure 1]. Error! Bookmark not defined. Thus, it was expected that other bicyclo[7.3.1]phosphates would have similar stereoselectivities.

To confirm this, trienes $(S, S, S)$-3.1 and $(R, R, S)$-3.2 were synthesized via the coupling of chiral, non-racemic alcohol $(S)$-3.3 with monochlorophosphates $(S, S)$-1.4 and $(R, R)-1.5$ (Scheme 3). In the case of $(S, S, S)-3.1$, subsequent RCM afforded the corresponding product cis-3.4 as a single diastereomer (E-configured olefin) in good yield. However, attempts at RCM with diastereomeric $(R, R, S)-3.5$-even under forcing conditions (12 mol \% G-II catalyst, refluxing toluene, $24 \mathrm{~h}$ )-were unsuccessful. This result was interesting, as stereochemistry in the side-chain of the olefin tether-partner (excluding the C3-position) did not inhibit RCM in the previous examples of bicyclo[7.3.1]phosphates en route to dictyostatin (see bicyclo[7.3.1]phosphates in Figure 1). Error! Bookmark not defined. Thus, we postulate that the stereochemistry at $C 3$ of the olefin tether-partner is most influential in the success of the RCM reaction for 10-membered ring formation. 


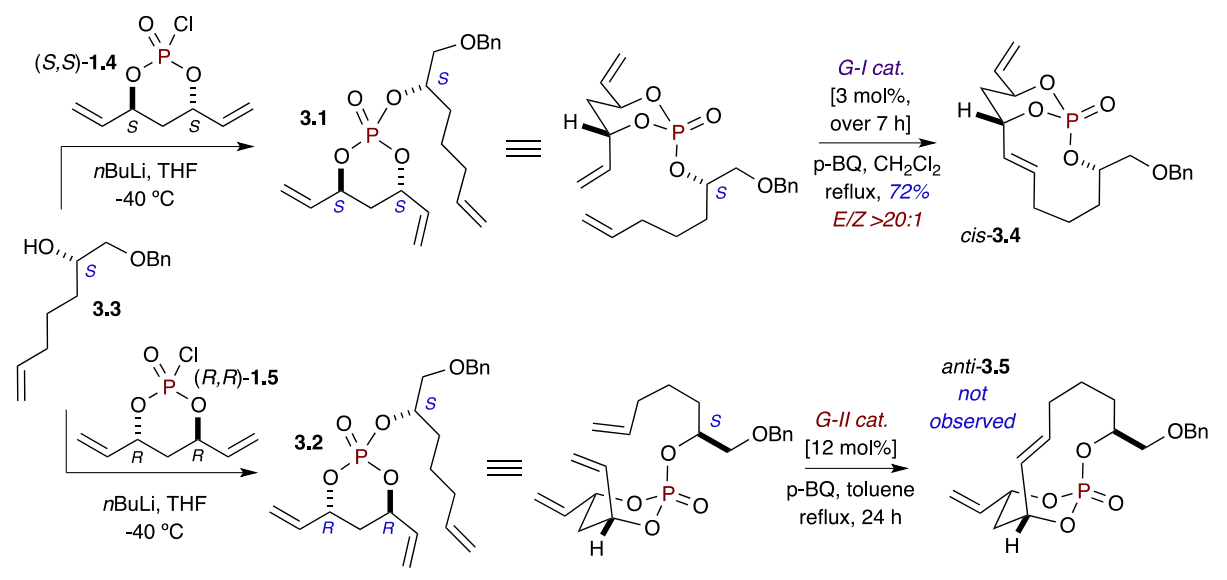

Scheme 3 Synthesis of branched bicyclo[7.3.1]phosphates.

To confirm the effect of C3-stereochemistry of the olefin tether-partner on the $\mathrm{RCM}$ reaction for bicyclo[7.3.1]phosphate formation, triene $(R, R)-4.1$ was synthesized via an analogous coupling of 5-hexen-1-ol with monochlorophosphates $(R, R)-\mathbf{1 . 5}$ (Scheme 4). Initial studies with the G-II catalyst provided only dimer formation even at high dilution (1 $\mathrm{mM}$ ) within very short reaction times (30-45 minutes). Gratifyingly, treatment of triene $(R, R)-\mathbf{4 . 1}$ with the G-I catalyst (added in $1 \mathrm{~mol} \%$ portions over $6 \mathrm{~h}$ ) in refluxing dichloromethane provided the desired product $\mathbf{4 . 2}$ in moderate yield $(74 \%$ yield brsm). This stark difference in reactivity implicates that C3-stereochemistry is a crucial factor in the successful formation of bicyclo[7.3.1]phosphates, presumably by long-range stereochemical induction.
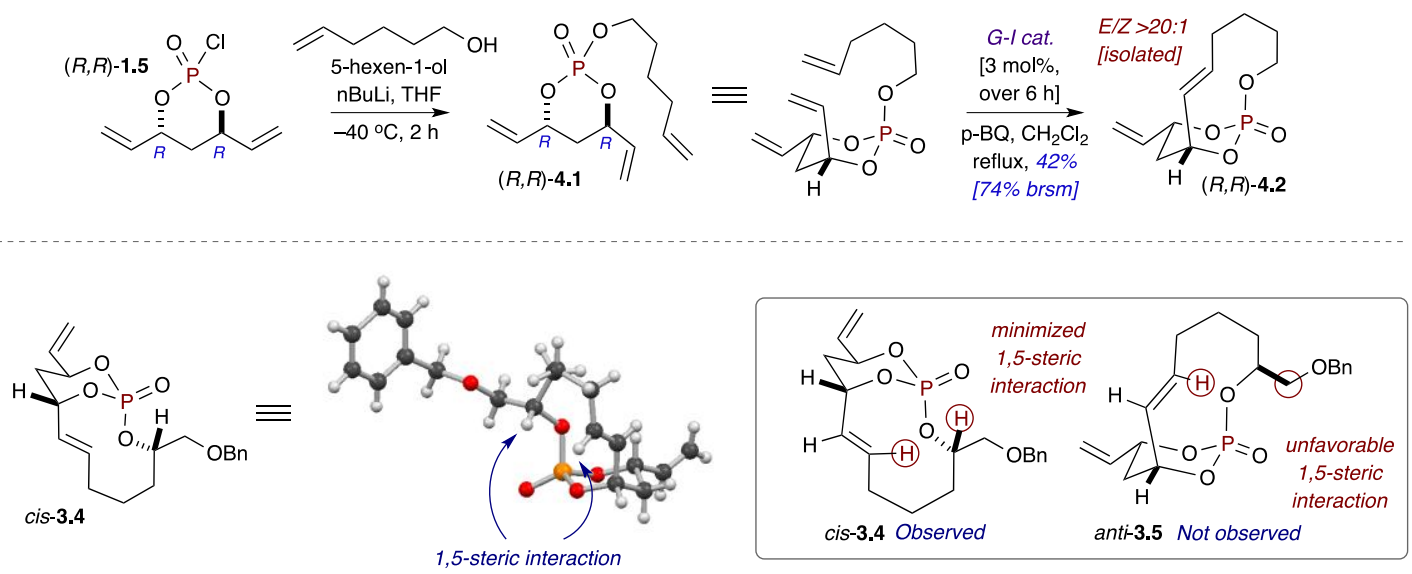

Scheme 4 Synthesis of simple bicyclo[7.3.1]phosphate 4.2 and X-ray analysis and effect of transannular ring strain in the formation of bicyclo[7.3.1]phosphates.

This reasoning was further bolstered by X-ray crystallographic analysis of cis-3.4, where a 1,5-interaction was observed between the $\mathrm{C}-\mathrm{H}$ substituent of the formed, endocyclic double bond and the $\mathrm{C}-\mathrm{H}$ bond at the $\mathrm{C} 3$-position of the tether-partner (Scheme 4). While previous mechanistic arguments for the RCM reaction involved the interaction of the intermittent ruthenium metallocyclobutane with another substituent on the ring (vide infra, see Figure 3), the analogous argument for larger ring systems may be too simplistic, given the complexity of large ring dynamics, as well as the stereochemistry of the forming double bond. However, based solely on the conformations of the product, a pronounced 1,5-steric interaction between the 
substituents on the endocyclic olefin and the C3-position of the olefin tether-partner could be responsible for the observed reactivity. When the C3-substituent of the olefinic tether-partner is hydrogen, the reaction proceeds-presumably because this 1,5interaction is minimized when both interacting groups are hydrogen; however, when the substituent is larger than hydrogen, this unfavorable 1,5-interaction is large enough to prevent the reaction from proceeding.

\subsection{Synthesis of P-stereogenic bicyclo[8.3.1]phosphates}

Studies were extended to include RCM of 11-membered rings to generate bicyclo[8.3.1]phosphates. In a similar fashion, diastereomeric trienes $\mathbf{5 . 1}$ and $\mathbf{5 . 2}$ were formed via the coupling of alcohol 5.3 with monochlorophosphates $(S, S)$-1.4 and $(R, R)$ 1.5. While RCM of $(S, S, S)-\mathbf{5 . 1}$ proceeded smoothly in the presence of the G-II $(69 \%$ yield) catalyst to provide bicyclo[8.3.1]phosphate 5.4, the corresponding RCM of $(R, R, S)-5.2$ did not provide the desired product. Though the source of this observed reactivity is still under investigation, the complex ring dynamics of these larger ring systems within the context of the bicyclic phosphate framework may be responsible for stark differences in reactivity with respect to stereochemistry at the C3-position of the alcohol tether-partner.

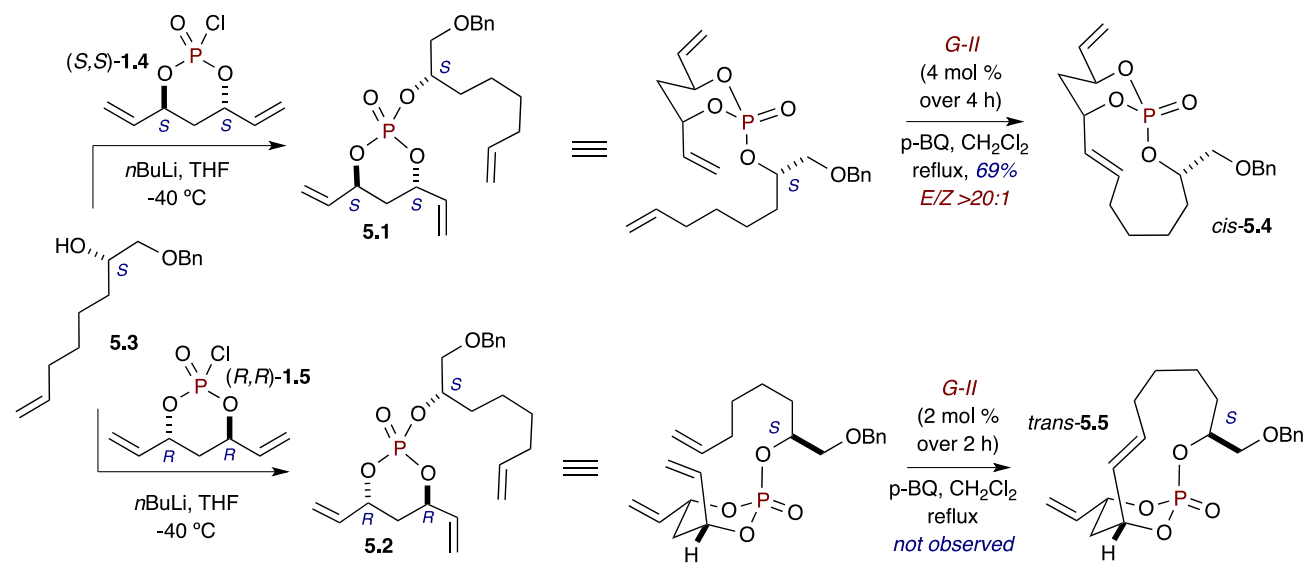

Scheme 5 Synthesis of P-stereogenic bicyclo[8.3.1]phosphates.

\section{Conclusion}

In summary, a number of simple and complex $P$-stereogenic bicyclo[n.3.1]phosphates have been generated via phosphate tether-mediated desymmetrization of $C_{2}$-symmetric 1,3-anti diol dienes via RCM. This work augments

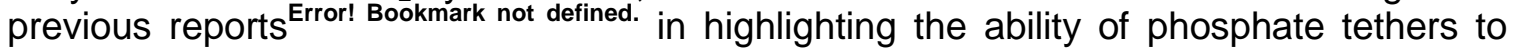
mediate the coupling of simple and complex olefin tether-partners with a variety of $C_{2}$ symmetric diene-diol substrates. In addition, a mechanistic rationale for the observed reactivity based upon proposed Ru-metallocyclobutane intermediate structures was developed, which may aid in predicting successful outcomes for complex couplings of similar substrates for natural product synthesis. Further investigation of the importance of the bicyclic framework, as well as complexity of ring dynamics due to ring size, on the success of RCM facilitated by phosphate tethers is in progress and will be reported in due course.

\section{Experimental Section}

\subsection{General}


All reactions were carried out in oven- or flame-dried glassware under argon atmosphere using standard gas-tight syringes, cannulae, and septa. Stirring was achieved with oven-dried magnetic stir bars. $\mathrm{Et}_{2} \mathrm{O}$, THF and $\mathrm{CH}_{2} \mathrm{Cl}_{2}$ were purified by passage through a purification system (Solv-Tek) employing activated $\mathrm{Al}_{2} \mathrm{O}_{3}$ (Grubbs, R. H.; Rosen. R. K.; Timmers, F. J. Organometallics 1996, 15, 1518-1520). $\mathrm{Et}_{3} \mathrm{~N}$ was purified by passage over basic alumina and stored over $\mathrm{KOH}$. Butyllithium was purchased from Aldrich and titrated prior to use. All olefin metathesis catalysts were acquired from Materia and used without further purification. Flash column chromatography was performed with Sorbent Technologies (30930M-25, Silica Gel 60A, 40-63 $\square \mathrm{m}$ ) and thin layer chromatography was performed on silica gel $60 \mathrm{~F}_{254}$ plates (EM-5717, Merck). Deuterated solvents were purchased from Cambridge Isotope laboratories. ${ }^{1} \mathrm{H}$ and ${ }^{13} \mathrm{C}$ NMR spectra were recorded in $\mathrm{CDCl}_{3}$ (unless otherwise mentioned) on a Bruker DRX-500 spectrometer operating at $500 \mathrm{MHz}$, and $125 \mathrm{MHz}$, respectively and calibrated to the solvent peak. ${ }^{31} \mathrm{P} N \mathrm{NM}$ spectra was recorded on Bruker DRX-400 spectrometer operating at $162 \mathrm{MHz}$. Highresolution mass spectrometry (HRMS) was recorded on a LCT Premier Spectrometer (Micromass UK Limited) operating on ESI (MeOH). Observed rotations at $589 \mathrm{~nm}$, were measured using AUTOPOL IV Model automatic polarimeter. IR was recorded on Shimadzu FTIR-8400S instrument.

\subsection{General procedure for preparation of monocyclic phosphate triesters}

To a solution of alcohol $(1.1 \mathrm{mmol})$ in THF $(2.9 \mathrm{~mL})$, at $-40 \stackrel{\circ}{\mathrm{C}}$ under argon, was added $n$-BuLi $(2.5 \mathrm{M}, 1.0 \mathrm{mmol})$, dropwise. The mixture was allowed to stir for 5 minutes, at which point a solution of phosphate monochloride $(1.5 \mathrm{mmol})$ in THF $(1 \mathrm{~mL})$ was slowly cannulated to the reaction vessel. The mixture was stirred at $-40 \stackrel{\circ}{ } \mathrm{C}$ for 2 hours (monitored by TLC) and was quenched with $3 \mathrm{~mL}$ of aqueous $\mathrm{NH}_{4} \mathrm{Cl}$ (sat.). The biphasic solution was separated, and the aqueous layer was extracted EtOAc $(3 \times 5 \mathrm{~mL})$. The combined organic layers were washed with brine, dried $\left(\mathrm{Na}_{2} \mathrm{SO}_{4}\right)$, and concentrated under reduced pressure. Purification via flash chromatography (Hexanes:EtOAc eluent) provided triene-containing monocyclic phosphate triester product.

\subsection{General procedure for ring-closing metathesis reactions to bicyclo[6.3.1]phosphates}

To a flask containing monocyclic phosphate triester $(1 \mathrm{mmol})$ in $\mathrm{CH}_{2} \mathrm{Cl}_{2}$ (dry, degassed, $0.007 \mathrm{M})$, equipped with an argon inlet and reflux condenser, was added $\left(\mathrm{ImesH}_{2}\right)\left(\mathrm{PCy}_{3}\right)(\mathrm{Cl})_{2} \mathrm{Ru}=\mathrm{CHPh}(\mathbf{G}-\mathrm{II})(3 \mathrm{~mol} \%),{ }^{24}$ and the reaction mixture was heated to reflux. Upon completion (monitored by TLC), the reaction was cooled to room temperature and concentrated under reduced pressure. Purification via flash chromatography (Hexanes:EtOAc eluent) provided bicyclo[6.3.1]phosphate.

\subsection{General procedure for ring-closing metathesis reactions to bicyclo[7.3.1]- and bicyclo[8.3.1]phosphates}

To a flask containing monocyclic phosphate triester (1 mmol) in $\mathrm{CH}_{2} \mathrm{Cl}_{2}$ (dry, degassed, $0.001 \mathrm{M})$, equipped with an argon inlet and reflux condenser, was added $p$ benzoquinone (10 mol \%). Then, G-I or G-II catalyst [see reaction schemes, vide supra] was added to the reaction [portion-wise over the allotted reaction time], and the reaction mixture was heated to reflux. Upon completion (monitored by TLC), the reaction was cooled to room temperature and concentrated under reduced pressure. Purification via flash chromatography (Hexanes:EtOAc eluent) provided the corresponding bicyclic phosphate.

\subsection{Characteristic of new compounds}


4.5.1 (4S,6S)-2-(((S)-1-(benzyloxy)hex-5-en-2-yl)oxy)-4,6-divinyl-1,3,2-dioxaphosphinane 2-oxide (1.1) Yield: 60\%. FTIR (neat): 2917, 2359, 1641, 1454, 1281, 1119, 991, 926, 750, 698, $667 \mathrm{~cm}^{-1} ;[\alpha]_{\mathrm{D}}=+48.94\left(c=0.66, \mathrm{CHCl}_{3}\right) ;{ }^{1} \mathrm{H} \mathrm{NMR}\left(500 \mathrm{MHz}, \mathrm{CDCl}_{3}\right) \delta$ 7.31-7.21 (m, 5H, aromatic), 6.01 (dddd, $J=17.0,10.7,6.2,0.8 \mathrm{~Hz}, 1 \mathrm{H}$, $\left.\mathrm{H}_{2} \mathrm{C}=\mathrm{C} \underline{\mathrm{HCHO}}(\mathrm{P}) \mathrm{CH}_{2}\right)$, 5.82-5.70 (m, 2H, $\left.\mathrm{H}_{2} \mathrm{C}=\mathrm{C} \underline{\mathrm{HCHO}}(\mathrm{P}) \mathrm{CH}_{2}, \mathrm{H}_{2} \mathrm{C}=\mathrm{CHCH}_{2} \mathrm{CH}_{2}\right), 5.33-$ $5.30\left(\mathrm{~m}, 1 \mathrm{H}, \underline{\mathrm{H}}_{2} \mathrm{C}=\mathrm{CHCHO}(\mathrm{P}) \mathrm{CH}_{2}\right), 5.29-5.27\left(\mathrm{~m}, 1 \mathrm{H}, \underline{\mathrm{H}}_{2} \mathrm{C}=\mathrm{CHCHO}(\mathrm{P}) \mathrm{CH}_{2}\right), 5.22$ (dt, J $\left.=10.6,1.2 \mathrm{~Hz}, 1 \mathrm{H}, \quad \underline{\mathrm{H}}_{2} \mathrm{C}=\mathrm{CHCHO}(\mathrm{P}) \mathrm{CH}_{2}\right), 5.17(\mathrm{dt}, J=10.6,1.2 \mathrm{~Hz}, 1 \mathrm{H}$, $\left.\underline{\mathrm{H}}_{2} \mathrm{C}=\mathrm{CHCHO}(\mathrm{P}) \mathrm{CH}_{2}\right), 5.01-4.89\left(\mathrm{~m}, 4 \mathrm{H}, \underline{\mathrm{H}}_{2} \mathrm{C}=\mathrm{CHCH}_{2} \mathrm{CH}_{2}, \mathrm{H}_{2} \mathrm{C}=\mathrm{CHCHO}(\mathrm{P}) \mathrm{CH}_{2}\right), 4.60-$ $4.54\left(\mathrm{~m}, 1 \mathrm{H}, \mathrm{CHO}(\mathrm{P}) \mathrm{CH}_{2} \mathrm{OBn}\right), 4.52\left(\mathrm{~d}, J=12.0 \mathrm{~Hz}, 1 \mathrm{H}, \mathrm{OCH}_{2} \mathrm{Ph}\right), 4 . \overline{45}(\mathrm{~d}, J=12.0 \mathrm{~Hz}$, $1 \mathrm{H}, \mathrm{OCH}_{2} \mathrm{Ph}$ ), 3.56 (ddd, $\left.J=10.7,3.9,1.3 \mathrm{~Hz}, 1 \mathrm{H}, \mathrm{CHO}(\mathrm{P}) \underline{\mathrm{CH}}_{2} \mathrm{OBn}\right), 3.52$ (dd, $J=10.6$, $\left.5.6 \mathrm{~Hz}, 1 \mathrm{H}, \mathrm{CHO}(\mathrm{P}) \mathrm{CH}_{2} \mathrm{OBn}\right), 2.18-2.07\left(\mathrm{~m}, 2 \mathrm{H}, \mathrm{H}_{2} \mathrm{C}=\mathrm{CHCH}_{2} \mathrm{CH}_{2}\right), 2.08-2.02(\mathrm{~m}, 1 \mathrm{H}$, $\mathrm{H}_{2} \mathrm{C}=\mathrm{CHCHO}(\mathrm{P}) \mathrm{CH}_{2} \mathrm{CHO}[\mathrm{P}]$ ), 1.96 (dddd, $J=14.7,5.6,3.8,1.8 \mathrm{~Hz}, 1 \mathrm{H}$, $\left.\mathrm{H}_{2} \mathrm{C}=\mathrm{CHCHO}(\mathrm{P}) \mathrm{CH}_{2} \mathrm{CHO}[\mathrm{P}]\right), 1.86-1.76\left(\mathrm{~m}, 1 \mathrm{H}, \mathrm{CH}_{2} \mathrm{CH}_{2} \mathrm{CHO}[\mathrm{P}] \mathrm{CH}_{2} \mathrm{OBn}\right), 1.76-1.68$ (m, $\left.1 \mathrm{H}, \mathrm{CH}_{2} \mathrm{CH}_{2} \mathrm{CHO}[\mathrm{P}] \mathrm{CH}_{2} \mathrm{OBn}\right) ;{ }^{13} \mathrm{C}$ NMR $\left(126 \mathrm{MHz}, \overline{\mathrm{CDCl}}_{3}\right) \delta 137.9,137.5,135.3$ (d, $\left.J_{\mathrm{CP}}=5.9 \mathrm{~Hz}\right), 135.2\left(\mathrm{~d}, J_{\mathrm{CP}}=1.8 \mathrm{~Hz}\right), 128.4(2 \mathrm{C}), 127.7(2 \mathrm{C}), 127.68,117.9,117.1$, 115.2, $77.9\left(\mathrm{~d}, J_{\mathrm{CP}}=6.7 \mathrm{~Hz}\right), 77.6\left(\mathrm{~d}, J_{\mathrm{CP}}=6.2 \mathrm{~Hz}\right), 75.8\left(\mathrm{~d}, \mathrm{~J}_{\mathrm{CP}}=6.2 \mathrm{~Hz}\right), 73.2,71.7(\mathrm{~d}$, $\left.J_{\mathrm{CP}}=4.1 \mathrm{~Hz}\right), 35.3\left(\mathrm{~d}, J_{\mathrm{CP}}=7.4 \mathrm{~Hz}\right), 31.4\left(\mathrm{~d}, J_{\mathrm{CP}}=5.0 \mathrm{~Hz}\right), 29.2 ;{ }^{31} \mathrm{P}$ NMR $(162 \mathrm{MHz}$, $\left.\mathrm{CDCl}_{3}\right) \delta$-7.9; HRMS calcd. for $\mathrm{C}_{20} \mathrm{H}_{27} \mathrm{O}_{5} \mathrm{PNa}(\mathrm{M}+\mathrm{Na})^{+} 401.1494$; found 401.1485 (TOF MS ES+).

4.5.2 (1S,3S,8S, 10S,Z)-3-((benzyloxy)methyl)-10-vinyl-2,11,12-trioxa-1-phosphabicyclo[6.3.1]dodec-6-ene 1-oxide (1.6) Yield: 60\%. FTIR (neat): 2924, 2359, 1718, 1452, 1283, $\left.1117,1092,989,852,565 \mathrm{~cm}^{-1} ;[\alpha]_{\mathrm{D}}=-5.03 \stackrel{\circ}{\circ} \mathrm{c}=0.78, \mathrm{CHCl}_{3}\right) ;{ }^{1} \mathrm{H} \mathrm{NMR}(500 \mathrm{MHz}$, $\left.\mathrm{CDCl}_{3}\right) \delta$ 7.31-7.20 (m, 5H, aromatic), 5.83-5.78 (m, $\left.1 \mathrm{H}, \mathrm{H}_{2} \mathrm{C}-\mathrm{HC}=\mathrm{CHCHO}(\mathrm{P}) \mathrm{CH}_{2}\right)$, 5.78-5.72 $\left(\mathrm{m}, 1 \mathrm{H}, \quad \mathrm{H}_{2} \mathrm{CHC}=\mathrm{CHCHO}(\mathrm{P}) \mathrm{CH}_{2}\right), 5.39-5.28\left(\mathrm{~m}, 2 \mathrm{H}, \underline{\mathrm{H}}_{2} \mathrm{C}=\mathrm{CHCHO}[\mathrm{P}]\right.$, $\left.\mathrm{HC}=\mathrm{CHCHO}(\mathrm{P}) \mathrm{CH}_{2}\right), 5.20\left(\mathrm{dt}, J=10.6,1.2 \mathrm{~Hz}, 1 \mathrm{H}, \underline{\mathrm{H}}_{2} \mathrm{C}=\mathrm{CHCHO}[\mathrm{P}]\right), 5.10(\mathrm{~d}, J=11.8$ $\mathrm{Hz}, 1 \mathrm{H}$ ), 5.02 (ddd, $\left.J=11.8,5.5,1.4 \mathrm{~Hz}, 1 \mathrm{H}, \mathrm{H}_{2} \mathrm{C}=\mathrm{CH}-\mathrm{CHO}(\mathrm{P}) \mathrm{CH}_{2}\right), 4.83-4.74(\mathrm{~m}, 1 \mathrm{H}$, $\left.\mathrm{CHO}(\mathrm{P}) \mathrm{CH}_{2} \mathrm{OBn}\right), 4.55\left(\mathrm{~d}, J=12.1 \mathrm{~Hz}, 1 \mathrm{H}, \mathrm{OCH}_{2} \mathrm{Ph}\right), 4.47(\mathrm{~d}, J=12.1 \mathrm{~Hz}, 1 \mathrm{H}$, $\mathrm{OC} \underline{\mathrm{H}}_{2} \mathrm{Ph}$ ), 3.49 (dd, $\left.J=10.4,4.5 \mathrm{~Hz}, 1 \mathrm{H}, \mathrm{CHO}(\mathrm{P}) \mathrm{C}_{2} \mathrm{OBn}\right), 3.45$ (dd, $J=10.4,5.3 \mathrm{~Hz}$, $\left.1 \mathrm{H}, \quad \mathrm{CHO}(\mathrm{P}) \mathrm{CH}_{2} \mathrm{OBn}\right), 2.92-2.83\left(\mathrm{~m}, 1 \mathrm{H}, \quad \mathrm{HC}=\mathrm{CHCH}_{2} \mathrm{CH}_{2}\right), 2.19-2.13(\mathrm{~m}, 1 \mathrm{H}$, $\left.\mathrm{H}_{2} \mathrm{C}=\mathrm{CHCHO}(\mathrm{P}) \mathrm{C}_{2} \mathrm{CHO}[\mathrm{P}]\right), 2.13-2.07\left(\mathrm{~m}, 1 \mathrm{H}, \mathrm{HC}=\mathrm{CH}-\underline{\mathrm{H}}_{2} \mathrm{CH}_{2}\right), 1.85-1.77(\mathrm{~m}, 1 \mathrm{H}$, $\left.\mathrm{CH}_{2} \mathrm{CH}_{2} \mathrm{CHO}[\mathrm{P}] \mathrm{CH}_{2} \mathrm{OBn}\right), \quad 1.76-1.65 \quad\left(\mathrm{~m}, \quad 2 \mathrm{H}, \quad \overline{\mathrm{HC}}=\mathrm{CHCHO}(\mathrm{P}) \mathrm{CH}_{2} \mathrm{CHO}[\mathrm{P}]\right.$, $\left.\mathrm{CH}_{2} \mathrm{C}_{2} \mathrm{CHO}[\mathrm{P}] \mathrm{CH}_{2} \mathrm{OBn}\right) ;{ }^{13} \mathrm{C}$ NMR $\left(126 \mathrm{MHz} \mathrm{CDCl}_{3}\right) \delta 138.0,137.3,135.2$ (d, $J_{\mathrm{CP}}=$ $9.8 \mathrm{~Hz}$ ), $128.3(2 \mathrm{C}), 127.7(2 \mathrm{C}), 127.6,124.2,117.3\left(\mathrm{~d}, J_{\mathrm{CP}}=1.4 \mathrm{~Hz}\right), 79.7$ (d, $J_{\mathrm{CP}}=5.6$ $\mathrm{Hz}), 77.02\left(\mathrm{~d}, J_{\mathrm{CP}}=7.7 \mathrm{~Hz}\right), 76.8\left(\mathrm{~d}, J_{\mathrm{CP}}=6.5 \mathrm{~Hz}\right), 73.2,72.7\left(\mathrm{~d}, J_{\mathrm{CP}}=4.7 \mathrm{~Hz}\right), 37.4(\mathrm{~d}$, $J_{\mathrm{CP}}=6.5 \mathrm{~Hz}$ ), $29.3\left(\mathrm{~d}, J_{\mathrm{CP}}=2.3 \mathrm{~Hz}\right), 25.4 ;{ }^{31} \mathrm{P} \mathrm{NMR}\left(162 \mathrm{MHz}, \mathrm{CDCl}_{3}\right) \delta-8.4 ; \mathrm{HRMS}$ calcd. for $\mathrm{C}_{18} \mathrm{H}_{23} \mathrm{O}_{5} \mathrm{PNa}(\mathrm{M}+\mathrm{Na})^{+} 373.1181$; found 373.1161(TOF MS ES+).

\section{Supplementary Data}

For full characterization, as well as spectral information, of all new compounds, see the provided supporting information.

\section{Acknowledgements}

This investigation was generously supported by funds provided by the National Institute of General Medical Sciences (NIH RO1 GM077309-7). The authors thank Justin Douglas and Sarah Neuenswander in the University of Kansas NMR Laboratory and Dr. Todd Williams for HRMS analysis. Support for the NMR instrumentation was provided by NSF Grant \#9512331, \#9977422, \#0320648 and NIH Center Grant \#P20 GM103418, \#S10RR024664 and \#S10 OD016360.We kindly acknowledge Dr. Victor Day of the Molecular Structure Group (MSG) at the University of Kansas for X-ray analysis (NSF- 
MRI grant CHE-0923449). The authors thank the University of Kansas and the State of Kansas for support of our program. The authors also thank Materia, Inc. for supplying metathesis catalyst. 


\section{References Cited:}

[1] For an excellent secondary source/collection of reviews, see: Metathesis in Natural Product Synthesis: Strategies, Substrates and Catalysts; Cossy, J.; Areniyadis, S.; Meyer, C., Eds.; Wiley-VCH, Weinheim, Germany, 2010.

[2] For an exceptional collection of reviews on current advances in olefin metathesis, see: Handbook of Metathesis, 2nd ed.; Grubbs, R. H. and O'Leary, D. J., Eds.; Wiley-VCH: Weinheim, Germany, 2015; Vol. 2.

[3] Monfette, S.; Fogg, D. In Green Metathesis Chemistry; Dragutan, V., Demonceau, A., Dragutan, I., Finkelshtein, E., Eds.; Springer Netherlands: 2010, p 129-156.

[4] (a) Evans, P. A. Temporary Silicon-Tethered Ring-Closing Metathesis Reactions in Natural Product Synthesis. In Metathesis in Natural Product Synthesis. Cossy, J.; Areniyadis, S.; Meyer, C., Eds.; Wiley-VCH,Weinheim, Germany, 2010, p. 225259; (b) Cusak, A. Chem. Eur. J. 2012, 18, 5800-5824.

[5] Hoye, T. R.; Promo, M. A. Tetrahedron Lett. 1999, 40, 1429-1432.

[6] (a) Evans, P. A.; Cui, J.; Buffone, G. P. Angew. Chem., Int. Ed. 2003, 42, 17341737. (b) Matsui, R.; Seto, K.; Fujita, K.; Suzuki, T.; Nakazaki, A.; Kobayashi, S. Angew. Chem., Int. Ed. 2010, 49, 10068-10073.

[7] (a) Burke, S. D.; Mueller, N.; Beaudry, C. M. Org. Lett. 1999, 1, 1827-1829; (b) Burke, S. D.; Voight, E. A. Org. Lett. 2001, 3, 237-240; (c) Voight, E. A.; Rein, C.; Burke, S. D. J. Org. Chem. 2002, 67, 8489-8499. (d) Van Hooft, P. A. V.; Leeuwenburgh, M. A.; Overkleeft, H. S.; Van Der Marel, G. A.; Van Boeckel, C. A. A.; Van Boom, J. H. Lett. 1998, 39, 6061-6064. (e) Scholl, M.; Grubbs, R. H. Tetrahedron Lett. 1999, 40, 1425-1428. (f) Ghosh, S. K.; Hsung, R. P.; Wang, J. Tetrahedron Lett. 2004, 45, 5505-5510. (g) Ghosh, S. K.; Ko, C.; Liu, J.; Wang, J.; Hsung, R. P. Tetrahedron 2006, 62, 10485-10496.

[8] Schmidt, B.; Kunz, O. Eur. J. Org. Chem. 2012, 2012, 1008-1018.

[9] (a) Whitehead, A.; McReynolds, M. D.; Moore, J. D.; Hanson, P. R. Org. Lett. 2005, 7, 3375-3378; (b) Whitehead, A.; McParland, J. P.; Hanson, P. R. Org. Lett. 2006, 8, 5025-5028; (c) Thomas, C. D.; McParland, J. P.; Hanson, P. R. Eur. J. Org. Chem. 2009, 5487-5500.

[10] The naming system used within this document is a short-hand description designed to aid the reader by emphasizing the type of bicyclic system formed in each RCM reaction. The proper names of each bicyclic phosphate are reported in the supporting information and will be denoted as references throughout the manuscript. In this case, bicyclo[4.3.1]phosphates refers to "2,9,10-trioxa-1phosphabicyclo[4.3.1]dec-4-ene 1-oxides."

[11] Hanson, P. R.; Chegondi, R.; Nguyen, J.; Thomas, C. D.; Waetzig, J.; Whitehead, A. J. Org. Chem. 2011, 76, 4358-4370.

[12] Chegondi, R.; Tan, M. M. L.; Hanson, P. R. J. Org. Chem. 2011, 76, 3909-3916.

[13] Venukadasula, P. K. M.; Chegondi, R.; Maitra, S.; Hanson, P. R. Org. Lett. 2010, 12, 1556-1559.

[14] Jayasinghe, S.; Venukadasula, P. K. M.; Hanson, P. R. Org. Lett. 2014, 16, 122 125.

[15] Chegondi, R.; Hanson, P. R. Synthetic studies to lyngbouilloside: a phosphate tether-mediated synthesis of the macrolactone core. Tetrahedron Lett. 2015, 56, Manuscript In Press. 
[16] Chegondi, R.; Maitra, S.; Markley, J. L.; Hanson, P. R. Chem. Eur. J. 2013, 19, 8088-8093.

[17] Formally, phosphate tether installation results in formation of a cyclic, pseudo- $C_{2}$ symmetric phosphate triene, whereby the homotopic olefins of the starting $\mathrm{C}_{2}$-symmetric diene are rendered diastereotopic upon tether installation (one olefin is cis to the allyloxy phosphate appendage, and one is cis to the $\mathrm{P}=\mathrm{O}$ ). This triene (RCM precursor) contains a chirotopic, non-stereogenic phosphorus atom, which after diastereoselective RCM between the two cis-substituted olefins, becomes $P$-stereogenic. The overall process has been previously described by Schreiber and others as terminus differentiation or diastereotopic differentiation of pseudo- $C_{2}$-symmetric substrates, see (a) Poss, C. S.; Schreiber, S. L. Acc. Chem. Res. 1994, 27, 9-17. For a review of both diastereotopic and enantiotopic differentiation, see (b) Magnuson, S. R. Tetrahedron 1995, 51, 21672213. For additional representative examples of diastereotopic differentiation, see: (c) Shephard, J. N.; Na, J.; Myles, D. C. J. Org. Chem. 1997, 62, 4558-4559. (d) Huwe, C. M.; Velder, J.; Blechert, S. Angew. Chem., Int. Ed. Engl. 1996, 35, 2376-2378. (e) Huwe, C. M.; Blechert, S. Synthesis 1997, 61-67. (d) Burke, S. D.; Müller, N.; Beaudry, C. M. Org. Lett. 1999, 1, 1827-1829. (f) Lautens, M.; Hughes, G. Angew. Chem., Int. Ed. Engl. 1999, 38, 129-131.

[18] For additional representative examples of diastereotopic and enantiotopic differentiation to $P$-stereogenic heterocycles using RCM, see (a) Stoianova, D. S.; Hanson, P. R. Org. Lett. 2000, 2, 1769-1772. (b) Moore, J. D.; Sprott, K. T.; Wrobleski, A. D.; Hanson, P. R. Org. Lett. 2002, 4, 2357-2360. (c) Dunne, K. S., Bisaro, F., Odell, B., Paris, J. M., and Gouverneur, V. J. Org. Chem. 2005, 70, 10803-10809. (d) Harvey, J. S., Malcolmson, S. J., Dunne, K. S., Meek, S. J., Thompson, A. L., Schrock, R. R., Hoveyda, A. H., and Gouverneur, V. Angew. Chem. Int. Ed. 2009, 48, 762-766. (e) Harvey, J. S., Giuffredi, G. T., and Gouverneur, V. Org. Lett. 2010, 12, 1236-1239.

[19] In previous work in generating complex medium to large, $P$-stereogenic bicyclo[n.3.1]phosphates where we do not remove the tether, we have at times referred to the RCM process as "diastereoselective" since it accentuates the formation of a single $P$-stereogenic center in the diastereotopic differentiation step of the cyclic pseudo- $C_{2}$ symmetric phosphate trienes.

[20] "Bicyclo[5.3.1]phosphates" refers to "2,10,11-trioxa-1-phosphabicyclo[5.3.1] undec5-ene 1-oxides" and "2,10,11-trioxa-1-phosphabicyclo[5.3.1]undec-4-ene 1-oxides."

[21] "Bicyclo[7.3.1]phosphates" refers to "2,12,13-trioxa-1-phosphabicyclo[7.3.1]tridec7-ene 1-oxides."

[22] "Bicyclo[6.3.1]phosphates refers to "2,11,12-trioxa-1-phosphabicyclo[6.3.1]dodec5-ene 1 oxides" and "2,11,12-trioxa-1-phosphabicyclo[6.3.1]dodec-6-ene 1-oxides."

[23] "Bicyclo[8.3.1]phosphates" refers to "2,13,14-trioxa-1-phosphabicyclo[8.3.1]tetradec-8-ene 1 oxides."

[24] M. Scholl, S. Ding, C. W. Lee, R. H. Grubbs, Org. Lett. 1999, 1, 953-956.

[25] The cis-/trans- descriptors in cis-1.6 and trans-1.7 refer to the relative stereochemistry between the substituents at C3 and C8 in the bicyclo[6.3.1]phosphates.

[26] For comparison with Si-tether mediated RCM, see references 6.

[27] The syn,anti- descriptors used in compounds cis, anti-2.9 and cis, syn-2.10 refer to the relative stereochemistry between the substituents at C3 and C4 in the bicyclo[6.3.1]phosphates.

[28] As molecular modeling and subsequent energy calculations for potential conformations of high-energy Ru-metallocyclobutane intermediates are 
challenging, we propose potential intermediate structures based upon observed product structures (confirmed by X-ray crystallography). For examples where this rationale is applied to describe a similar observation made in all carbon-based RCM, see: Liu, J.; Lotesta, S. D.; Sorensen, E. J. Chem. Commun. 2011, 47, 1500-1502.

[29] All X-ray crystallographic data has been submitted to the Cambridge Crystallographic Data Centre, and the structures were assigned the following deposition numbers: cis-2.4 [905669], cis, anti-2.9 [905670], cis-3.4 [1058400].

[30] For a recent review on general ring-closing metathesis, see: Hanson, P.R.; Maitra, S.; Chegondi, R.; Markley, J. L. General Ring-Closing Metathesis. In Handbook of Metathesis, 2nd ed.; Grubbs, R. H. and O'Leary, D. J., Eds.; Wiley-VCH: Weinheim, Germany, 2015; Vol. 2. p 1-170. 